\title{
Odour and colour polymorphism in the food-deceptive orchid Dactylorhiza romana
}

\section{Journal Article}

\section{Author(s):}

Salzmann, C. C.; Schiestl, F. P.

Publication date:

2007

\section{Permanent link:}

https://doi.org/10.3929/ethz-b-000006516

\section{Rights / license:}

In Copyright - Non-Commercial Use Permitted

\section{Originally published in:}

Plant Systematics and Evolution 267(1-4), https://doi.org/10.1007/s00606-007-0560-z 


\title{
Odour and colour polymorphism in the food-deceptive orchid Dactylorhiza romana
}

\author{
C. C. Salzmann ${ }^{1}$ and F. P. Schiestl ${ }^{1,2}$ \\ ${ }^{1}$ Plant Ecological Genetics, Institute of Integrative Biology, ETH Zürich, Switzerland \\ ${ }^{2}$ Present address: Institute of Systematic Botany, University of Zürich, Switzerland
}

Received May 9, 2006; accepted April 16, 2007

Published online: August 1, 2007

(C) Springer-Verlag 2007

\begin{abstract}
The food deceptive orchid, Dactylorhiza romana (Sebastiani) Soó exhibits a colour polymorphism with yellow, red, and intermediate orange morphs. In this study we tested if floral odour differed among the three distinct colour morphs. We identified 23 odour compounds in D. romana, and all of them occurred in the three colour morphs. Monoterpenes dominated the floral scent. On the basis of Euclidean distances of relative amounts of compounds, yellow morphs were closer to each other than to orange or red morphs. Differentiation of the morphs was mainly due to linalool and benzaldehyde. Linalool occurred in low relative amounts in the yellow morphs, but in high amounts in some of the red individuals, whereas benzaldehyde occurred in higher relative amounts in yellow morphs. Linalool and benzaldehyde are known to be important signal-substances in plant-insect communication, however, it remains to be shown whether insects can discriminate between flower morphs on the basis of the here shown odour differences.
\end{abstract}

Key words: Floral scent, linalool, rewardless flowers, flower mimicry, pollination.

\section{Introduction}

In insect-pollinated plants, pollinators usually associate floral signals, such as colour or scent, with reward. Pollinator visitation is generally correlated with plant fitness, and thus we expect stabilizing selection mediated by associative learning to create uniformity in these traits. This seems contradictory to the fact that polymorphisms of floral traits have been found in many plant species, mainly in colour, where morphs are often also discrete (Kay 1978). Variability in odour compounds within populations has also been found (Olesen and Knudsen 1994, Knudsen 2002, Dötterl et al. 2005), however, variability in this trait is often continuous, but can also be discrete, as in the case of Polemonium viscosum, where distinct scent morphs have been found (Galen and Kevan 1980).

Polymorphism of floral traits in rewarding plants may be maintained by contrasting preferences of individuals belonging to the same or different pollinator species for particular flower morphs (Kay 1978, Galen 1985), or when pollinator composition differs in space and time (Galen and Kevan 1980). Other factors than pollinator-mediated selection can also contribute to polymorphism, e.g. when morphs respond differently to environmental factors and accordingly vary in their fitness (Schemske and Bierzychudek 2001). In 
some polymorphic species, certain morphs are consistently underrepresented. Morphs might experience reduced fitness because they are actively discriminated against by pollinators (Waser and Price 1983, Stanton 1987), but may also suffer reduced fitness because of inferior viability, or reduced production of inflorescences and flowers (Wolfe 1993, Levin and Brack 1995, Jones 1996). Such morphs may be maintained in populations for example by high mutation rates (Levin and Brack 1995). Compensatory selection pressures, unrelated to pollination, may also contribute to maintain these morphs, e.g. when morphs are less attractive to herbivores or show elevated responses to herbivore damage (Strauss et al. 2004, Irwin and Strauss 2005).

Many orchids though do not reward their pollinators but attract them by general food advertising signals (Ackerman 1986, Nilsson 1992). In such food deceptive flowers, polymorphism of floral traits have been hypothesised to be a strategy to delay avoidance learning of the pollinators (Heinrich 1975, Nilsson 1992, Moya and Ackerman 1993). While visiting artificial flowers which differed in colour, bumblebees tended to switch between different colour morphs after an unrewarding visit (Smithson and Macnair 1997). This behaviour could result in an advantage of rare colour morphs and induce negative frequency dependent selection on corolla colour or other floral traits (Gigord et al. 2001). However, a survey of natural populations of Dactylorhiza sambucina, which exhibits a colour polymorphism, showed no higher pollination success of rare morphs (Pellegrino et al. 2005, Jersakova et al. 2006).

Polymorphisms in floral signals may not be independent but a result of a correlation with other floral traits. Such correlation have been repeatedly documented, colour for example was found to be associated with flower size, flower display, and the number of inflorescences (Galen et al. 1987, Wolfe 1993, Wolfe and Sellers 1997, Gómez 2000), and the two floral scent morphs in Polemonium were associated with differing flower size (Galen et al. 1987).
Some floral odour compounds are known to share biosynthetic pathways with certain flower pigments, e.g. mono- and sesquiterpenes are common odour compounds (e.g. myrcene, linalool, $\alpha$-farnesene), whereas some tetraterpenes (carotenoids) are pigments responsible for yellow, orange and red flower colour. Some benzenes (e.g. methyl benzoate, cinnamic aldehyde) share pathways with anthocyanes pigments, which are responsible for blue, purple and orange flower colour (Dixon and Paiva 1995, McGarvey and Croteau 1995). Partial blockage of the anthocyane pathway in Dianthus for instance resulted in a reduced expression of anthocyanes, but increased emission of the volatile benzenoid methyl benzoate (Zuker et al. 2002). However, to our knowledge, this is the only molecular study looking at scent and colour in combination, and there are only a few other studies that investigated the correlation between particular colour morphs and their scent production (Galen and Kevan 1980, Olesen and Knudsen 1994, Büsser 2004).

The Mediterranean orchid Dactylorhiza romana (Sebastiani) Soó exhibits a yellow/red flower colour dimorphism within populations and flowers early in spring (Delforge 2001). Besides the two distinct colour morphs an intermediate light red or orange morph also exists that may be produced by continuous introgression between the two morphs (Nilsson 1980). Dactylorhiza romana does not provide any reward to its pollinators but relies on general food advertising signals to deceive them. It is pollinated mainly by bumblebee queens and various other bees (Nilsson 1980, Cozzolino et al. 2005).

In this study we analysed the variability of odour compounds within the three colour variants of $D$. romana and tested if scent emission was distinct between the colour morphs.

\section{Materials and methods}

Scent collection. Scent collection was conducted in Cilento National Park, Province of Salerno, Southern Italy. Because the morphs showed a patchy 
distribution, plants were sampled from six sites with $500 \mathrm{~m}$ minimum distance: site 1: $5 \mathrm{red}, 2$ orange, 2 yellow individuals; site 2: 3 red, 1 orange individual; site 3: 3 red, 1 orange individual; site 4: 1 red individual; site 5: 1 orange individual; site 6: 18 yellow individuals. Odour was collected by headspace sorption by covering the inflorescence with a polyethylene terephtalate (PET) cooking bag $\left(\right.$ Nalophan $\left.^{\circledR}\right)$ and pulling out air out of the bags by a battery operated vacuum pump (SKC Inc.) at a rate of between 12 and $114 \mathrm{ml} / \mathrm{min}$ (Huber et al. 2005). Volatiles were trapped on $2.5 \mathrm{mg}$ of Porapak $\mathrm{Q}$ in a glass tube. Before use, the Porapak was cleaned with $100 \mu$ l dichlormethane and $100 \mu \mathrm{l}$ of a hexane/acetone mixture (9:1). Ambient air was collected as control samples to identify background contamination. After a sampling period from 3-7 hours, adsorbed volatiles were eluted from the Porapak with $50 \mu 1$ of a mixture of hexane:acetone (9:1). Samples were sealed in glass vials and stored at $-20^{\circ} \mathrm{C}$.

Quantitative GC analyses and GC-Mass spectrometry. Floral compounds were kindly identified by Roman Kaiser (Givaudan Schweiz AG, Dübendorf, Switzerland). For quantitative analysis, $100 \mathrm{ng}$ of n-octadecane was added to each scent sample as an internal standard. One $\mu \mathrm{l}$ of each sample was injected splitless at $40^{\circ} \mathrm{C}(1 \mathrm{~min})$ into a gas chromatograph (gcAgilent $6890^{\circ} \mathrm{N}$ ) followed by opening of the split valve and programming to $230^{\circ} \mathrm{C}$ at a rate of $2.5^{\circ} \mathrm{C} / \mathrm{min}$. The GC was equipped with an INOWAX column $(30 \mathrm{~m} \times 0.32 \mathrm{~mm} \varnothing \times 0.25 \mu \mathrm{m}$ film thickness, Agilent Technologies). Hydrogen was used as "carrier gas" and nitrogen as "make up gas".

Relative amounts of each compound in a sample were calculated by dividing the absolute amount of each compound by the sum of all compounds. Absolute amounts of odor compounds were calculated using the internal standard method (Schomburg 1990). Sampling times and sampling volumes were used to calculate the absolute amount per liter sampled air and hour and plant.

Statistical analyses. We compared the relative amounts of each odour compound emitted between all three colour morphs. Because the data were not normally distributed and variances were not homogeneous, we used the nonparametric Mann-Whitney U-test. We multiplied the P-values obtained from each test by 3 to account for the number of all possible comparisons (Bonferroni correction for multiple tests). The coefficient of variance
(C.V. = standard deviation $/$ mean) was calculated for each compound in all morphs.

To compare if the scent composition within morphs differed from between morphs, we calculated a dissimilarity matrix based on Euclidean distances (Levin et al. 2001, Ashman et al. 2005). To do so, we standardized for each sample the relative amounts of each compound to a mean of 0 and variance of 1 (i.e. $Z$ scores). With a Welch ANOVA for unequal variances we tested if mean Euclidean distances within and between colour morphs overall differed and with a subsequent Tamhane's T2-test we compared mean Euclidean distances between all morphs. Lower dissimilarity between individuals of the same morph than between individuals of different morphs indicated that variation between morphs is greater than variation within morphs (Levin et al. 2001). As a null hypothesis, we expected that intra-morph and inter-morph comparisons across all three colour morphs should show equal Euclidean distances; higher values for inter-morph Euclidean distances than intra-morph distances indicate a differentiation of the morphs.

\section{Results}

The scent profiles of the three colour morphs of D. romana consisted of 23 compounds which were all present in the three colour morphs (Table 1). The scent profile of D. romana mainly consisted of monoterpenes, such as $\beta$-pinene, sabinene, limonene, $\beta$-phellandrene, (E)-ocimene and trans-sabinene hydrate. The fraction of monoterpenes made up at least $60 \%$ of the scent profile in all three colour morphs. The quantitative variation of compounds among individuals was nevertheless considerable (see min and max values in Table 1). Mean relative amounts of compounds did not differ between morphs, with exception of linalool and benzaldehyde. Linalool occurred only in $65 \%$ of the yellow morphs but in all of the orange and red morphs, and relative amounts of this compound differed significantly between yellow and red morphs (Mann-Whitney U-test $\mathrm{U}=36, \mathrm{P}=0.003$ ). Two red individuals even contained exceptionally high amounts of linalool, $32 \%$ and $40 \%$, respectively (Fig. 1). Benz- 


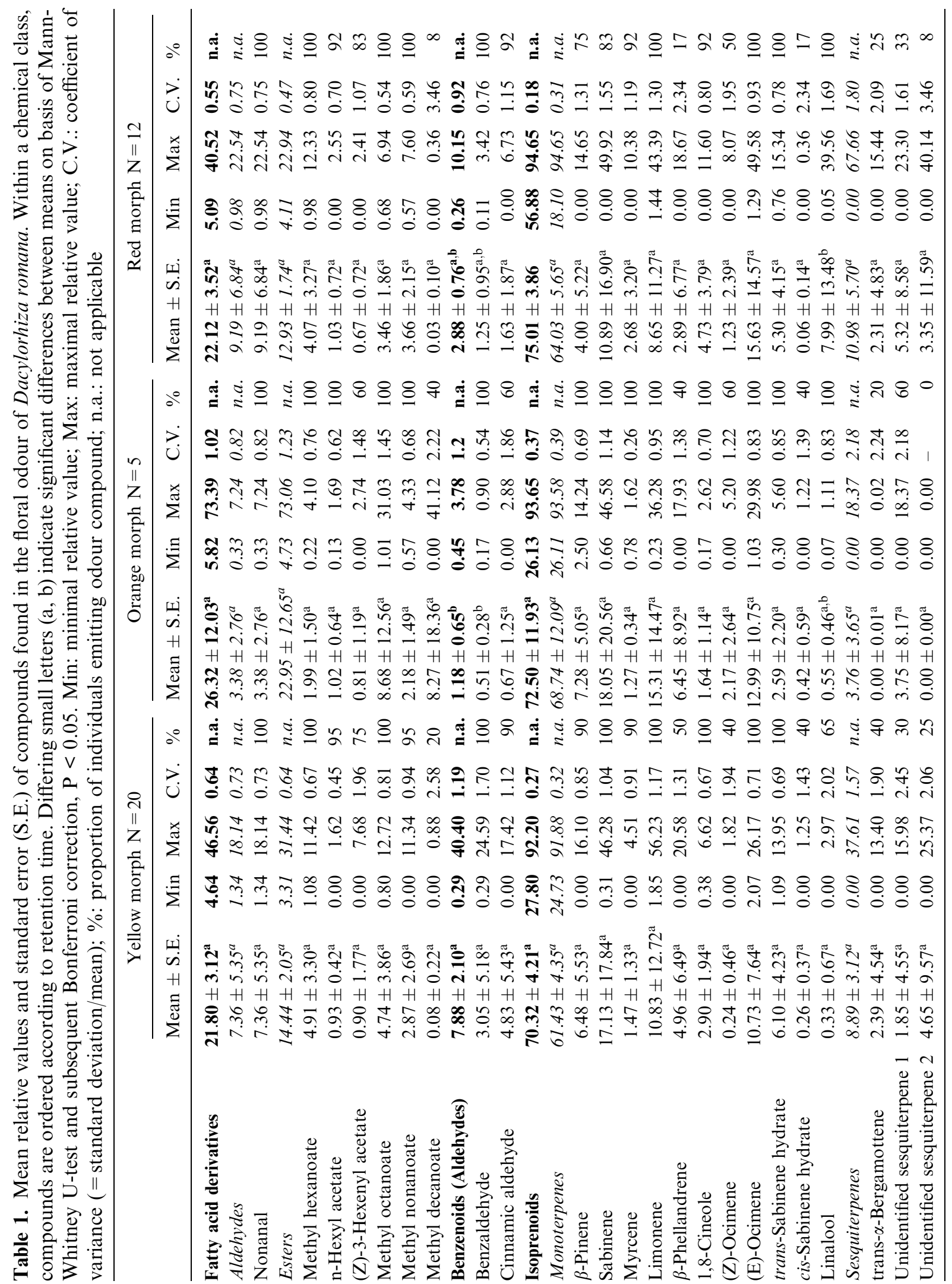




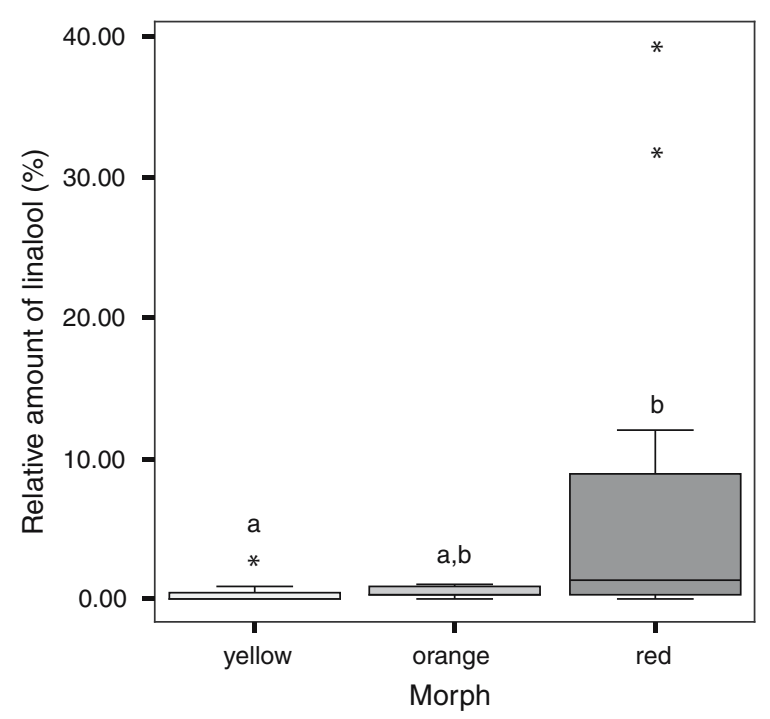

Fig. 1. Boxplots showing relative amounts of linalool in the three colour morphs. Boxes show interquartile ranges (between 25 and 75 quartile), and are divided by the median. Whiskers represent smallest or largest observations within 1.5 interquartile ranges of the bottom or the top of the boxes. Differing small letters (a, b) above boxplots indicate significant differences between medians on basis of Mann-Whitney U-test and subsequent Bonferroni correction, $\mathrm{P}<0.05$ ). Score distribution are the lower and upper parts of the box

aldehyde occurred in all individuals, but in significantly higher relative amounts in the yellow morphs (Mann-Whitney U-test $\mathrm{U}=10$, $\mathrm{P}=0.02$ ).

Euclidean distances within and/or between morphs were not equal (Welch ANOVA: Sum of squares $=157.839, \quad \mathrm{df}=5, \quad$ mean square $=31.568, \mathrm{~F}=8.771, \mathrm{p}<0.001$, corrected $\mathrm{R}$ squared $=0.055$ ). Yellow morphs were differentiated from orange or red morphs. This was shown by a higher intra-morph similarity of yellow individuals in comparison to intramorph similarity of orange and red individuals, however, the difference was only significant between the yellow and red morphs (Tamhane's T2, P $<0.001$; Fig. 2).

Accordingly, inter-morph distances were only significantly higher than intra-morph distances when compared with yellow individuals (Tamhane's T2, $\mathrm{P}=0.02$ (yellow/orange) and $\mathrm{P}=0.001$ (yellow/red), respectively).

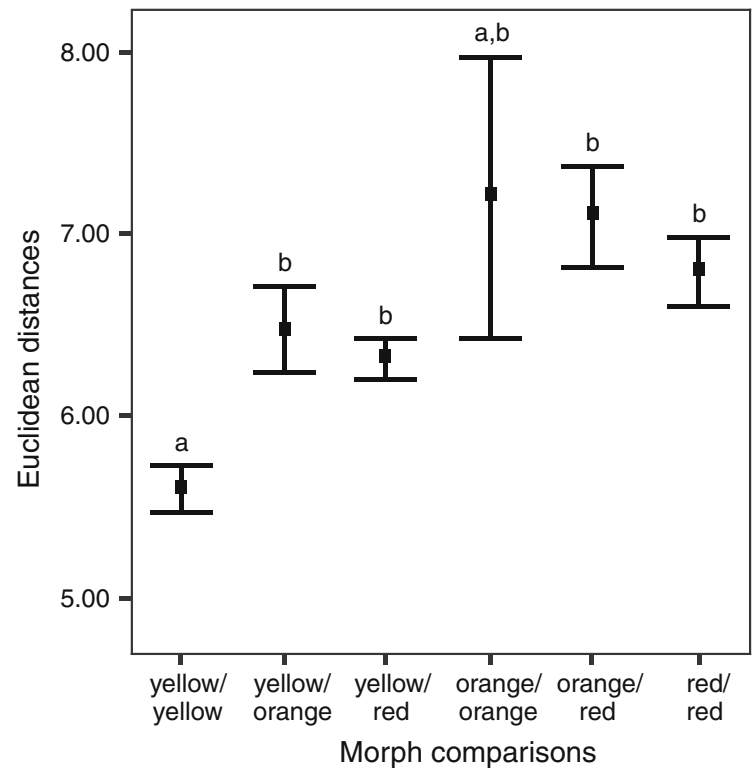

Fig. 2. Euclidean distances between intra-morph individuals and inter-morph individuals based on relative amounts of odour compounds. Lower values indicate higher similarity. Differing small letters $(a, b)$ above bars indicate significant differences between means on the basis of a Welch ANOVA with Tamhane's T2 post-hoc test, $\mathrm{P}<0.02$. Bars show means \pm S.E

\section{Discussion}

Monoterpenes were the dominating fraction in the scent profiles of all the three colour morphs of Dactylorhiza romana. Monoterpenes are also dominantly represented in other food deceptive orchids, such as Anacamptis morio, Dactylorhiza sambucina, Orchis mascula and O. pauciflora (Nilsson 1980, 1983, 1984; Salzmann unpublished results). However, high amounts of monoterpenes were also emitted by a whole range of food rewarding plants, which are also pollinated by bees or bumblebees (Groth et al. 1987, Borg-Karlson et al. 1994, Ashman et al. 2005, Gaskett et al. 2005).

Our comparison of colour morphs in $D$. romana showed that the monoterpene linalool and the benzenoid benzaldehyde differed in the mean relative amounts across morphs (Table 1, Fig. 1). Linalool is an important attractive odour compound and widely 
distributed among plants. Linalool does, however, not only occur in the flowers of many plants (Knudsen et al. 2006), but also in the mandibular glands of the solitary bee Colletes cunicularius, where it has a pheromonal function as mate attractant (Borg-Karlson et al. 2003, Mant et al. 2005). Behavioural experiments showed that honeybees are innately attracted to linalool (Henning et al. 1992), and a discrimination experiment between two odour stimulus (phenylacetaldehyde and linalool), which were either rewarding or unrewarding, gave indication that linalool may have an innate meaning for bumble bees, too (Laloi and Pham-Delegue 2004). A higher amount of linalool in the red morphs of D. romana is therefore interesting, because it could render red morphs more attractive to pollinators, possibly resulting in higher pollination success and fitness. So far, to our knowledge, there are no studies done on comparing morph fitness in natural populations of D. romana, however, in the related D. sambucina, a tendency for higher fitness of red morphs was not found (Pellegrino et al. 2005). Benzaldehyde is also a common compound and occurrs in many bee pollinated plants, but has up to now mostly been found behaviouraly active in moths (Schiestl and Marion-Poll 2002, Huber et al. 2005, Knudsen et al. 2006). Yet, the general view is that visual cues are the main means by which food deceptive species attract their pollinators (Nilsson 1980, 1983), and scent of D. romana was indeed faint to the human nose (pers. observation). If scent was not under selection, we would expect that bumblebees choose, after unrewarding visits to one morph, a different colour morph independent of its scent profile (Smithson and Macnair 1997). Unless scent and colour were correlated, we would not expect a scent differentiation of morphs. Instead, we would expect a comparable high variability and distribution of compounds within all morphs due to relaxed selection (Ackerman et al. 1997). The comparison of the Euclidean distances of the three morphs, however, showed that yellow morphs were different from orange or red individuals (Fig. 2), which indicates that some mechanism must keep the morphs apart.

Despite dissassortative mating between morphs, linalool could have accumulated in red morphs when inter-morph hybrids experience lower fitness. Thus, the acquirement of higher linalool expression, for example by alleles that increase enzyme activity of the linalool synthase (LIS), an enzyme that produces linalool (Raguso and Pichersky 1999), could be maintained preferentially in red morphs and not spread easily to other morphs. Evidence for inter-morph incompatibility comes from the related orchid $D$. sambucina (Pellegrino et al. 2005a, Jersakova et al. 2006).

Even though there seems to be some differentiation between yellow and red morphs due to linalool, relative amounts of linalool were in about half of the red morphs comparable to amounts in the yellow morphs (Fig. 1). It seems unlikely therefore that morph colour and fragrance are tightly associated through mechanisms such as pleiotropy or linkage. Similarly, an association between scent and colour in the related D. sambucina was also not found by Nilsson (1980). In another study, a correlation between scent and colour was found between yellow and red morphs in Mimulus aurantiacus (Büsser 2004), where red morphs are mainly hummingbird pollinated and yellow morphs bee pollinated. In Corydalis cava however, which exhibits a red/white colour dimorphism, the scent profiles varied a lot between individual plants regardless of flower colour (Olesen and Knudsen 1994), and similarly were the light blue or purple morphs in Polemonium viscosum not correlated with the distinct sweet or skunky smell of the plants.

In conclusion, our results give evidence for some scent differentiation between colour morphs, as yellow morphs were different from orange and red morphs. Colour and scent do not seem to be to be correlated, and scent differentiation may be a by-product of inter-morph incompatibility. Future studies should conduct behavioural tests to find out 
if the here shown differences between morphs are pronounced enough to be detected by pollinators.

We sincerely thank Roman Kaiser (Givaudan Schweiz AG, Dübendorf, Switzerland) for identification of floral odour compounds, Antonio M. Nardella, Olga De Castro, Stefania Impagliazzo, and Giovanni Scopece for helping with fieldwork and Salvatore Cozzolino for fruitful discussions (Università degli studi di Napoli "Federico II", Naples, Italy). This study was financially supported by the by the Federal Institute of Technlogy Zürich (ETH internal research grant 28/01-4 to F. P. Schiestl).

\section{References}

Ackerman J. D. (1986) Mechanisms and evolution of food-deceptive pollination systems in orchids. Lindleyana 1: 108-113.

Ackerman J. D., Méléndez-Ackerman E. J., Salguero-Faria, J. (1997) Variation in pollinator abundance and selection on fragrance phenotypes in an epiphytic orchid. Amer. J. Bot. 84: 1383-1390.

Ashman T. L., Bradburn M., Cole D. H., Blaney B. H., Raguso R. A. (2005) The scent of a male: The role of floral volatiles in pollination of a gender dimorphic plant. Ecology 86: 2099-2105.

Borg-Karlson A. K., Tengö J., Valterova I., Unelius C. R., Taghizadeh T., Tolasch T., Francke W. (2003) (S)-(+)-linalool, a mate attractant pheromone component in the bee Colletes cunicularius. J. Chem. Ecol. 29: 1-14.

Borg-Karlson A. K., Valterova I., Nilsson L. A. (1994) Volatile compounds from flowers of six species in the family Apiaceae: bouquets for different pollinators? Phytochemistry 35: 111119.

Büsser D. (2004) Floral signals and pollination syndromes in three morphs of Mimulus aurantiacus. Geobotanical Institute. Federal Institute of Technology (ETH), Zurich.

Cozzolino S., Schiestl F. P., Müller A., De Castro O., Nardella A. M., Widmer A. (2005) Evidence for pollinator sharing in Mediterranean nectar-mimic orchids: absence of premating barriers? Proc. Roy. Soc. London, B 272: 1271-1278.
Delforge P. (2001) Guide des Orchidées d'Europe, d'Afrique du Nord et du Proche-Orient. Delachaux et Niestlé, Lausanne.

Dixon R. A., Paiva N. L. (1995) Stress-induced phenylpropanoid metabolism. Pl. Cell 7: 10851097.

Dötterl S. L., Wolfe M., Jürgens A. (2005) Qualitative and quantitative analyses of flower scent in Silene latifolia. Phytochemistry 66: 203-213.

Galen C. (1985) Regulation of seed-set in Polemonium viscosum: Floral scents, pollination, and resources. Ecology 66: 792-797.

Galen C., Kevan P. G. (1980) Scent and color, floral polymorphisms and pollination biology in Polemonium viscosum Nutt. Amer. Midl. Naturalist 104: 281-289.

Galen C., Zimmer K. A., Newport M. E. (1987) Pollination in floral scent morphs of Polemonium viscosum: a mechanism for disruptive selection on flower size. Evolution 41: 599-606.

Gaskett A., Conti E., Schiestl F. (2005) Floral odor variation in two heterostylous species of Primula. J. Chem. Ecol. 31: 1223-1228.

Gigord L. D. B., Macnair M. R., Smithson A. (2001) Negative frequency-dependent selection maintains a dramatic flower color polymorphism in the rewardless orchid Dactylorhiza sambucina (L.) Soò. Proc. Natl. Acad. Sci. (USA) 98: 6253-6255.

Gómez J. M. (2000) Phenotypic selection and response to selection in Lobularia maritima: importance of direct and correlational components of natural selection. J. Evol. Biol. 13: 689699.

Groth I., Bergström G., Pellmyr O. (1987) Floral fragrances in Cimicifuga: Chemical polymorphism and incipient speciation in Cimicifuga simplex. Biochem. Syst. Ecol. 15: 441-444.

Heinrich B. (1975) Bee flowers: a hypothesis on flower variety and blooming times. Evolution 29: 325-334.

Henning J. A., Peng Y. S., Montague M. A., Teuber L. R. (1992) Honey bee (Hymenoptera: Apidae) behavioral response to primary alfalfa (Rosales, Fabaceae) floral volatiles. J. Econ. Entomol. 85: 233-239.

Huber F. K., Kaiser R., Sauter W., Schiestl F. P. (2005) Floral scent emission and pollinator attraction in two species of Gymnadenia (Orchidaceae). Oecologia 142: 564-575.

Irwin R. E., Strauss S. Y. (2005) Flower color microevolution in wild radish: Evolutionary 
response to pollinator-mediated selection. Amer. Naturalist 165: 225-237.

Jersakova J., Kindlmann P., Renner S. S. (2006) Is the colour dimorphism in Dactylorhiza sambuci$n a$ maintained by differential seed viability instead of frequency-dependent selection? Folia Geobot. 41: 61-76.

Jones K. N. (1996) Pollinator behavior and postpollination reproductive success in alternative floral phenotypes of Clarkia gracilis (Onagraceae). Int. J. Pl. Sci. 157: 733-738.

Kay A. O. N. (1978) The role of preferential and assortative pollination in the maintenance of flower colour polymorphisms. In: Richards A. J. (ed.) Pollination of flowers by insects. Linnean Society Symposium Series No. 6, Academic Press, London, pp. 175-190.

Knudsen J. T. (2002) Variation in floral scent composition within and between populations of Geonoma macrostachys (Aracaceae) in the western Amazon. Amer. J. Bot. 89: 1772-1778.

Knudsen J. T., Erikkson R., Gershenzon J., Stahl B. (2006) Diversity and distribution of floral scent. Bot. Rev. 72: 1-120.

Laloi D., Pham-Delegue M. (2004) Bumble bees show asymmetrical discrimination between two odors in a classical conditioning procedure. J. Insect Behav. 17: 385-396.

Levin D. A., Brack E. T. (1995) Natural selection against white petals in Phlox. Evolution 49: 1017-1022.

Levin R. A., Raguso R. A., McDade L. A. (2001) Fragrance chemistry and pollinator affinities in Nyctaginaceae. Phytochemistry 58: 429-440.

Mant J., Brandli C., Vereecken N. J., Schulz C. M., Francke W., Schiestl F. P. (2005) Cuticular hydrocarbons as sex pheromone of the bee Colletes cunicularius and the key to its mimicry by the sexually deceptive orchid, Ophrys exaltata. J. Chem. Ecol. 31: 1765-1787.

McGarvey D. J., Croteau R. (1995) Terpenoid metabolism. Pl. Cell 7: 1015-1026.

Moya S., Ackerman J. D. (1993) Variation in the floral fragrance of Epidendrum ciliare (Orchidaceae). Nord. J. Bot. 13: 41-47.

Nilsson L. A. (1980) The pollination ecology of Dactylorhiza sambucina (Orchidaceae). Bot. Not. 133: 367-385.

Nilsson L. A. (1983) Anthecology of Orchis mascula (Orchidaceae). Nord. J. Bot. 3: 157-179.
Nilsson L. A. (1984) Anthecology of Orchis morio (Orchidaceae) at its out post in the worth. Nova Acta Regiae Societatis Scientiarum Upsaliensis V: C, 3, 167-179.

Nilsson L. A. (1992) Orchid pollination biology. Trends Ecol. Evol. 7: 255-259.

Olesen J. M., Knudsen J. T. (1994) Scent profiles of flower color morphs of Corydalis cava (Fumariaceae) in relation to foraging behavior of bumblebee queens (Bombus terrestris). Biochem. Syst. Ecol. 22: 231-237.

Pellegrino G., Caimi D., Noce M. E., Musacchio A. (2005) Effects of local density and flower colour polymorphism on pollination and reproduction in the rewardless orchid Dactylorhiza sambucina (L.) Soò. Pl. Syst. Evol. 251: 119-129.

Raguso R. A., Pichersky E. (1999) A day in the life of a linalool molecule: chemical communication in a plant-pollinator system. Part 1: Linalool biosynthesis in flowering plants. Pl. Spec. Biol. 14: 95-120.

Schemske D. W., Bierzychudek P. (2001) Perspective: evolution of flower color in the desert annual Linanthus parryae: wright revisited. Evolution 55: 1269-1282.

Schiestl F. P., Marion-Poll F. (2002) Detection of physiologically active flower volatiles using gas chromatography coupled with electroantennography. In: Jackson J. F., Linskens H. F. (eds.) Analyses of taste and aroma. Springer, Berlin, pp. 173-198.

Schomburg G. (1990) Gas chromatography. A practical course. VCH, Weinheim.

Smithson A., Macnair M. R. (1997) Negative frequency-dependent selection by pollinators on artificial flowers without rewards. Evolution 51: 715-723.

Stanton M. L. (1987) Reproductive biology of petal color variants in wild populations of Raphanus sativus: I. pollinator response to color morphs. Amer. J. Bot. 74: 178-187.

Strauss S. Y., Irwin R. E., Lambrix V. M. (2004) Optimal defence theory and flower petal colour predict variation in the secondary chemistry of wild radish. J. Ecol. 92: 132-141.

Waser N. M., Price M. V. (1983) Pollinator behavior and natural selection for flower color in Delphinium nelsonii. Nature 302: 422-424.

Wolfe L. M. (1993) Reproductive consequences of a flower color polymorphism in Hydrophyllum appendiculatum. Amer. Midl. Naturalist 129: 405-408. 
Wolfe L. M., Sellers S. E. (1997) Polymorphic floral traits in Linaria canadensis (Scrophulariaceae). Amer. Midl. Naturalist 138: 134-139.

Zuker A., Tzfira T., Ben-Meir H., Ovadis M., Shklarman E., Itzhaki H., Forkmann G., Martens S., Neta-sharir I., Weiss D., Vainstein A. (2002) Modification of flower color and fragrance by antisense suppression of the flavanone 3-hydroxylase gene. Molec. Breed. 9: 33-41.
Address of the authors: Charlotte C. Salzmann and Florian P. Schiestl (e-mail: florian.schiestl @ systbot.uzh.ch), Plant Ecological Genetics, Institute of Integrative Biology, ETH Zürich, Universitätsstrasse 16, 8092 Zürich, Switzerland. Present address: Institute of Systematic Botany, University of Zürich, Zollikerstrasse 107, 8008 Zürich. 